\title{
As Conferências Nacionais como Instrumento de Participação Democrática na Administração Pública da Saúde
}

\author{
The National Conferences as an Instrument of \\ Democratic Participation in Public Health Administration
}

Las conferencias nacionales como instrumento de

Participación democrática en la administración de salud pública

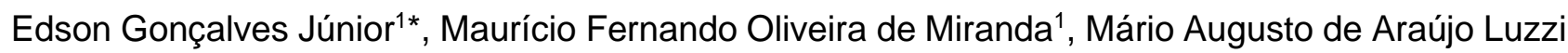
Júnior ${ }^{1}$, Aurélio Passos Silva1.
\end{abstract}

\section{RESUMO}

Objetivo: Analisar a importância, a sistemática e a efetividade das Conferências Nacionais de Saúde com o advento da Constituição Federal de 1988. Revisão Bibliográfica: Como estratégia metodológica abordou a revisão bibliográfica, e também por utilizar a revisão narrativa que fundamentará a discussão sobre os principais conceitos e peculiaridades que permeiam a temática. Efetivar-se-á através de levantamento bibliográfico a ser compilado com livros e artigos científicos no qual, os autores discorrem sobre o tema. Destacou-se o conceito de participação popular e sua efetividade com a redemocratização. Abordando ainda o histórico de criação das conferências nacionais, seu objetivo inicial e após a Constituição Federal, suas finalidades, processos participativos a fenomenologia política. Neste contexto, cabem algumas reflexões que fomentam a discussão e análise. De que forma a participação popular aparece nas Conferências Nacionais de Saúde? O tipo de democracia existente em nosso país favorece a participação e o protagonismo dos cidadãos? Tal instituto ocorre somente para cumprimento de uma formalidade ou realmente colaboram com a democracia contemporânea? Considerações Finais: Verifica-se que, com o advento da Constituição Federal de 1988, as conferências públicas tornaram-se importantes instrumentos de participação popular. Destaca-se a relevância das Conferências Nacionais de Saúde, pois possibilitam uma efetiva formulação de propostas para a criação de políticas públicas.

Palavras-chave: Conferências Nacionais, Democracia, Participação Popular.

\begin{abstract}
Objective: To analyze the importance, the systematic and the effectiveness of the National Health Conferences with the advent of the Federal Constitution of 1988. Literature review: as methodological strategy approached the bibliographic revision, and also by using the narrative revision that will base the discussion about the main concepts. and peculiarities that permeate the theme. It will be done through bibliographic survey to be compiled with books and scientific articles in which the authors discuss the theme. The concept of popular participation and its effectiveness with redemocratization stood out. Also addressing the history of creation of national conferences, their initial objective and after the Federal Constitution, their purposes, participatory processes and political phenomenology. In this context, some reflections fit the discussion and analysis. How does popular participation appear at National Health Conferences? Does the kind of democracy in our country favor the participation and protagonism of the citizens? Is such an institute only for the fulfillment of a formality or does it really collaborate with contemporary democracy? Final Considerations: With the advent of the Federal Constitution of 1988, public conferences became important instruments of popular participation. The relevance of the National Health Conferences stands out, as they enable an effective formulation of proposals for the creation of public policies.
\end{abstract}

Key words: National Conferences, Democracy, Popular Participation.

\footnotetext{
${ }^{1}$ Faculdade de Direito Milton Campos - Nova Lima - MG. *E-mail: advocaciaitabirito@gmail.com
} 


\section{RESUMEN}

Objetivo: Analizar la importancia, la sistemática y la efectividad de las Conferencias Nacionales de Salud con el advenimiento de la Constitución Federal de 1988. Revisión bibliográfica: como estrategia metodológica se acercó a la revisión bibliográfica, y también mediante el uso de la revisión narrativa que basará la discusión sobre los conceptos principales. y peculiaridades que impregnan el tema. Se realizará mediante una encuesta bibliográfica que se compilará con libros y artículos científicos en los que los autores discutan el tema. Se destacó el concepto de participación popular y su efectividad con la redemocratización. También aborda la historia de la creación de conferencias nacionales, su objetivo inicial y después de la Constitución Federal, sus propósitos, procesos participativos y fenomenología política. En este contexto, algunas reflexiones encajan en la discusión y el análisis. ¿Cómo aparece la participación popular en las conferencias nacionales de salud? ¿El tipo de democracia en nuestro país favorece la participación y el protagonismo de los ciudadanos? ¿Es este instituto solo para el cumplimiento de una formalidad o realmente colabora con la democracia contemporánea? Consideraciones finales: Con la llegada de la Constitución Federal de 1988, las conferencias públicas se convirtieron en instrumentos importantes de participación popular. Se destaca la relevancia de las Conferencias Nacionales de Salud, ya que permiten una formulación efectiva de propuestas para la creación de políticas públicas..

Palabras clave: Conferencias Nacionales, Democracia, Participación Popular.

\section{INTRODUÇÃO}

Com o advento da elaboração da Constituição Federal de 1988, a democracia passa a ter um papel fundamental dando voz aos cidadãos e propiciando protagonismo aos sujeitos, determinando tanto a representação política a ser escolhida diretamente pelo voto, quanto às políticas públicas a serem elaboradas (DALLARI DA, 2009). O artigo 1ํ do texto constitucional em seu parágrafo único assim estabelece:

"Todo o poder emana do povo, que o exerce por meio de representantes eleitos ou diretamente, nos termos desta Constituição" (BRASIL, 1988).

Assim, a carta magna é um marco para a democracia participativa, pois proporciona protagonismo aos sujeitos no processo decisório, na organização, formação e atuação do Estado, determinando tanto a representação política a ser escolhida diretamente pelo voto, quanto às políticas públicas a serem elaboradas. "O Estado Democrático de Direito coloca o povo como protagonista do processo decisório" (DALLARI DA, 2009). A Constituição da República Federativa do Brasil de 1988 em seu artigo 14 estabelece que:

"a soberania popular será exercida pelo sufrágio universal e pelo voto direto e secreto, com valor igual para todos e, nos termos da lei, mediante a: I- plebiscito; IIreferendo; III- iniciativa popular" (BRASIL, 2017).

Desta forma, verifica-se que a Carta Magna adotou a democracia semidireta, ou seja, com expressa participação popular para nortear todo ordenamento jurídico (AVRITZER L, 2016).

Para Lenza P (2014), a democracia semidireta ou participativa apresenta peculiaridades e atributos da democracia direta, o que propicia aos cidadãos a participação sobre os atos estatais. A obra de Figueiredo, (2007) afirma que o Estado somente poderá ser democrático se e quando o povo exercer efetivamente 0 poder por meio de seus representantes.

Neste contexto, cabem algumas reflexões que fomentam uma discussão e análise. De que forma a participação popular aparece na Administração Pública? O tipo de democracia existente em nosso país favorece a participação e o protagonismo dos cidadãos? Que tipo de política pública vem sendo desenvolvida no Estado Brasileiro? As Conferências Nacionais têm promovido a participação popular? Tal instituto ocorre somente para cumprimento de uma formalidade ou realmente colaboram com a democracia contemporânea?

É importante verificar se de fato os anseios e interesses da população condizem com as Políticas Públicas elaboradas pela Administração Pública na área de saúde. A lei 8.142 de 1990 estabeleceu uma nova dinâmica às políticas públicas de saúde e com a efetividade das Conferências de Saúde, instituiu-se encontros 
periódicos a cada quatro anos, com o objetivo de avaliar a saúde no âmbito nacional, bem como propor diretrizes para a formulação de Políticas Públicas para a saúde.

Desta forma, as Conferências Nacionais de Saúde visam proporcionar aos participantes a definição de prioridade e políticas a serem implementadas pelo executivo. É nesta perspectiva que este artigo se inicia, trata-se de uma pesquisa bibliográfica, cujo objetivo é analisar a importância, a sistemática e a efetividade das Conferências Nacionais de Saúde com o advento da Constituição Federal de 1988.

\section{REVISÃO BIBLIOGRÁFICA}

\section{Criação das conferências nacionais}

As Conferências Nacionais foram instituídas pelo Decreto Lei no 378 de 13 de janeiro 1937, em seu artigo 90, no Governo Vargas, pelo Ministro Gustavo Capanema, com o objetivo de ser uma estratégia de construção de aparato governamental voltado para coordenação e organização das ações em todo país, fortalecendo o controle e poder estatal (AVRITZER L, 2000).

Desta forma, assim estabelece o artigo 90 do decreto lei 378 de 1990 que instituiu as Conferências Nacionais de educação e saúde no Brasil.

"Art. 90. Fica instituída a Conferência Nacional de Educação e a Conferencia Nacional de Saúde, destinadas a facilitar ao Governo Federal o conhecimento das atividades concernentes à educação e à saúde, realizadas em todo o país, e a orientálo na execução dos serviços locais de educação e de saúde, bem como na concessão do auxílio e da subvenção federais. Parágrafo único. A Conferência Nacional de Educação e a Conferência Nacional de Saúde serão convocadas pelo Presidente da República, com intervalos máximos de dois anos, nelas tomando parte da autoridade administrativa que representem o Ministério da Educação e Saúde e os governos dos Estados, do Distrito Federal e do Território do Acre (Decreto Lei 378/90".

As primeiras Conferências Nacionais foram realizadas em 1941. Segundo Horta JSB (2000), a primeira conferência nacional de educação foi realizada em 03 de novembro e a conferência nacional de saúde, no dia 10 de novembro do mesmo ano.

O objetivo inicial, embora parecesse estabelecer a criação de diálogo entre Estado e População, tratavase de uma ampliação do Poder Estatal, ou seja, uma forma de controle em todos os níveis federativos. Assim, até a década de 80 , mesmo existindo a participação de representantes externos à estrutura governamental, estes não possuíam direito a voto, o que impossibilitava a efetividade da participação popular (AVRITZER L, 2000). O Brasil adotou em sua Constituição Federal de 1988 o Estado Democrático de Direito, conforme explicita o artigo $1^{\circ}$ da Carta Magna:

"Art. 1ํ A República Federativa do Brasil, formada pela união indissolúvel dos Estados e Municípios e do Distrito Federal, constitui-se em Estado Democrático de Direito e tem como fundamentos:

I - a soberania;

II - a cidadania;

III - a dignidade da pessoa humana;

$I V$ - os valores sociais do trabalho e da livre iniciativa;

$V$ - o pluralismo político.

Parágrafo único. Todo o poder emana do povo, que o exerce por meio de representantes eleitos ou diretamente, nos termos desta Constituição (BRASIL, 2017) ".

O Estado Democrático de Direito consiste em colocar o povo como protagonista do processo decisório, ou seja, o cidadão deixa de ser mero espectador e torna-se participante na organização, formação e atuação do Estado. O Estado Democrático de Direito estabelece que a efetiva participação popular deve nortear todas as decisões, ou seja, o povo organiza, forma e atua de maneira soberana o Estado (DALLARI DA, 2009). 
Para Modesto P (2002), a participação popular significa trata-se da interferência de terceiros na realização da função administrativa do Estado, implementada em favor de interesses da coletividade, por cidadão nacional ou representante de grupos sociais nacionais, estes últimos se é enquanto legitimados a agir em nome coletivo. Portanto, a participação popular visa estabelecer uma relação entre Estado-Sociedade de forma que qualquer cidadão intervenha nas decisões da Administração Pública, objetivando o bem comum para toda a sociedade.

Assim, sobre a importância da participação popular no processo democrático afirma-se que "a partir do momento em que a opinião pública for o fundamento da atuação dos governantes, a soberania popular será considerada princípio básico de governo" (MORAES ACF, 2007).

Com a criação do Sistema Único de Saúde (SUS), Lei 8.080 de 1990, a Administração Pública se viu na obrigação de trazer como resposta efetiva as diversas demandas sociais na área de saúde, sendo a forma mais efetiva para identificar cada necessidade regional e posteriormente a criação de diretrizes gerais para todos os níveis (HORTA JSB, 2000).

"Art. 1 o Esta lei regula, em todo o território nacional, as ações e serviços de saúde, executados isolada ou conjuntamente, em caráter permanente ou eventual, por pessoas naturais ou jurídicas de direito Público ou privado.

Art. $2^{\circ}$ A saúde é um direito fundamental do ser humano, devendo o Estado prover as condições indispensáveis ao seu pleno exercício.

$\S 1$ O O dever do Estado de garantir a saúde consiste na formulação e execução de políticas econômicas e sociais que visem à redução de riscos de doenças e de outros agravos e no estabelecimento de condições que assegurem acesso universal e igualitário às ações e aos serviços para a sua promoção, proteção e recuperação (Lei 8.080 de 1990)".

Desta maneira, com o advento da redemocratização, as conferências passam a ter um papel extremamente importante, pois passam de fato, a inserir o cidadão como protagonista do processo decisório. As conferências deixam de ter 0 arranjo de ampliação do poder estatal e passam a garantir a participação democrática da população com o objetivo de formular propostas a serem implementadas pelo Estado.

A Lei 8.142 de 1990 traz, portanto, novas diretrizes para as Conferências de Saúde. Institui encontros periódicos para avaliar a saúde no âmbito nacional, bem como propõe diretrizes para a formulação de Políticas Públicas.

"Art. $1^{\circ} \mathrm{O}$ Sistema Único de Saúde (SUS), de que trata a Lei $n^{\circ} 8.080$, de 19 de setembro de 1990, contará, em cada esfera de governo, sem prejuízo das funções do Poder Legislativo, com as seguintes instâncias colegiadas:

I - a Conferência de Saúde; e

II - o Conselho de Saúde.

$\S 1^{\circ} \mathrm{A}$ Conferência de Saúde reunir-se-á a cada quatro anos com a representação dos vários segmentos sociais, para avaliar a situação de saúde e propor as diretrizes para a formulação da política de saúde nos níveis correspondentes, convocada pelo Poder Executivo ou, extraordinariamente, por esta ou pelo Conselho de Saúde (Lei 8.142 de 1990)".

Desta forma, as Conferências Nacionais de Saúde visam proporcionar aos participantes a definição de prioridade e políticas a serem executadas pelo poder executivo. Assim, a sociedade civil participa ativamente no processo de formulação, gestão e decisão das políticas públicas a serem implementadas.

\section{A participação popular nas conferências nacionais}

Entende-se como "conferência um processo de diálogo e manifestação de opiniões para definição de uma agenda pública, marcado pela mobilização social e participação plural, viabilizado por mecanismos de representação" (AVRITZER L, 2013). Após a Constituição Federal de 1988 houve uma descentralização administrava e consequentemente uma ampliação da participação social. Participação Popular, portanto, é a 
interferência de terceiros na realização da função administrativa do Estado, realizada por cidadão nacional ou representante de grupos sociais nacionais em favor de interesses da coletividade (HORTA JSB, 2000). Desta forma, é necessário fazer uma análise de como ocorre a participação popular, que tipo de programas são realizados pela Administração Pública, até que ponto há interesse da real participação e valorização do cidadão nas tomadas de decisão.

Para Avritzer L (2013) a participação popular nas conferências nacionais são espaços de participação social. A sociedade civil e Estado refletem e decidem juntos sobre determinada política pública, gerando assim, resultados a serem incluídos nas agendas e ações do governo.

É importante também compreender como o Poder Público lida com o protagonismo dos cidadãos. As conferências abrem um importante espaço para a participação popular. Habermas J (1995), após a publicação da Teoria da Ação Comunicativa, traz a ideia da realização de um processo de deliberação coletiva, contando com a participação racional de todos os indivíduos interessados ou atingidos por tais decisões. Para ele, é fundamental que em cada ação e no caso do tema abordado, participação popular, haja um consenso comunicativo, bem como a construção de um conceito de mundo social reflexivamente adquirido.

Desta forma, Habermas J (1995) trabalha a questão do procedimentalismo como prática social e não como método de constituição de governo. Para o autor, as normas apenas são válidas quando todos os afetados concordam e participam racionalmente para a tomada de decisões.

Outro autor que trabalha a questão da teoria da democracia moderna é Häberle P (1997). Sua teoria democratizante da interpretação constitucional considera o povo protagonista na função de intérprete constitucional. Conforme abordado ao longo desta pesquisa, considera-se que a Constituição Brasileira de 1988 expressa-se como uma Constituição aberta, ou seja, possibilita ao cidadão uma efetiva participação popular.

No processo democrático de Conferências é oferecida a população maneiras diferentes de manifestar suas opiniões, debates, formulação de propostas, o que reforça o caráter de protagonismo do cidadão junto a sua atuação frente ao Estado, trazendo para a realidade a teoria habermaziana de criação de um processo de deliberação coletiva (AVRITZER L, 2000).

Assim, as conferências tornam-se uma excelente oportunidade de efetivar a realização de deliberação coletiva, onde todos têm a possibilidade de participação. Ao final de todo o processo, as propostas aprovadas são encaminhadas ao órgão responsável pela conferência para posterior regulamentação (AVRITZER L, 2013). Desta forma, a discussão sobre a participação popular na Administração Pública deve basilar a democracia, bem como verificar como as prioridades da população são definidas e se de fato são executadas.

\section{CONSIDERAÇÕES FINAIS}

Verifica-se que, com o advento da Constituição Federal de 1988, as conferências públicas tornaram-se importantes instrumentos de participação popular. Destaca-se a relevância das Conferências Nacionais de Saúde, pois possibilitam uma efetiva formulação de propostas para a criação de políticas públicas, apresentam para o Estado um diagnóstico da realidade nacional, o que minimiza sensivelmente a Administração Pública no cometimento de erros de avalição. As conferências trazem também uma avalição das ações e da realidade do sistema de saúde de uma forma geral, e estabelecem o fortalecimento da participação popular e a afirmação por parte da sociedade de ideias e compromissos. Neste instituto cria-se uma oportunidade de planejamento coletivo de políticas públicas sob a perspectiva mobilizatória política.

As Conferências Nacionais de Saúde tornam-se fundamentais uma vez que promovem a participação popular, contribuem de maneira efetiva com o Estado na criação de políticas públicas na saúde, identificando os problemas existentes nas mais diversas regiões do Brasil, possibilitando assim uma medida mais precisa no plano de ação a ser adotado pela Administração Pública. Portanto, as conferências fortalecem o caminho da democratização e a escuta de uma parcela da população, que se propõe a colaborar com o processo de discussão e planejamento das temáticas em pauta. 


\section{REFERÊNCIAS}

1. AVRITZER L, SOUZA C (Org.). Conferências nacionais: atores, dinâmicas participativas e efetividade. Brasília: Ipea, 2013.

2. AVRITZER L. Impasses da democracia no Brasil. Rio de Janeiro: Editora Civilização Brasileira, 2016, P. 49-64.

3. AVRITZER L. Teoria democrática e deliberação pública. Lua Nova, São Paulo, n. 50, 2000.

4. BRASIL, Coletânea de Legislação Administrativa, Constituição Federal. Organização Odete Medauar, 13를. São Paulo, Revista dos Tribunais, 2013.

5. BRASIL, Decreto Lei no 378 de 13 de janeiro de 1937. Institui a criação da Conferência Nacional de Educação e a Conferencia Nacional de Saúde.

6. BRASIL, Lei Federal o 8.080 de 19 de setembro de 1990. Institui a criação do Sistema Único de Saúde.

7. BRASIL. Lei Federal ํㅜ 8.142 de 28 de dezembro de 1990. Institui a criação do Conselho Nacional de Saúde.

8. BRASIL: Constituição da República Federativa do Brasil. 1988. Preâmbulo. Disponível em <http://www.planalto.gov.br/ccivil_03/Constituicao/Constituicao.htm>. Acesso em 02/10/2019.

9. DALLARI DA. Elementos de Teoria Geral do Estado. 28ª Ed. São Paulo, Editora Saraiva 2009. P. 59-152

10. FIGUEIREDO LV. Direito Público Estudos. Belo Horizonte, Editora Fórum 2007. P. 101-1536.

11. HÄBERLE P. Hermenêutica Constitucional. 1a Ed. Porto Alegre, Editor Sérgio Antônio Fabris, 1997. P. 15-48

12. HABERMAS J. Teoria de la Acción comunicativa: Complementos y estudios prévios. Madri, Editora Cátedra, 1995. P. $125-178$

13. HOCHMAN GF. Reformas, instituições e políticas de saúde no Brasil. Revista Educar, Curitiba 2005. P. 47-152

14. HORTA JSB. A I Conferência Nacional de Educação ou de como monologar sobre educação na presença de educadores In: GOMES, Angela M. de C. (Org.). Capanema: o ministro e seu ministério. p.143-172.; Rio de Janeiro: FGV, 2000.

15. LENZA P. Direito Constitucional Esquematizado. 18ª Ed. São Paulo, Editora Saraiva, 2014. 1452p.

16. MODESTO P. Participação Popular na Administração Pública. Mecanismos de Operacionalização (2002).

17. MORAES ACF. Administração Pública Transparente e Responsabilidade do Político. 1ª Ed. Belo Horizonte, Editora Fórum, 2007. 